\title{
Quantitative estimation of carbon removal effects due to wood utilization up to 2050 in Japan: effects from carbon storage and substitution of fossil fuels by harvested wood products
}

Received: November 17, 2009 / Accepted: December 9, 2009 / Published online: April 27, 2010

\begin{abstract}
Carbon absorbed by forests remains stored in the timber used for wood products, and a change in wood product stock can be evaluated as substantial removal/emission of atmospheric carbon. Since the carbon storage effect due to harvested wood products (HWP) might be taken into account in the future framework of carbon mitigation, it is crucial to estimate the carbon flow and stock concerning HWP for the next commitment period. In the present study, we developed a model for estimating the flow and stock of wood products in Japan's building, furniture, and paper sectors. The HWP carbon storage effect and substitution effect (carbon reduction by substituting fossil fuels and energy-intensive materials with HWP) up to 2050 were quantitatively estimated by lifetime analysis. Our model simulation revealed that (i) the carbon stock change in Japan due to HWP would be evaluated as a large emission if the atmospheric-flow approach is adopted, (ii) carbon removal would not significantly increase if the ratio of newly constructed wooden buildings/furniture remains stable, and (iii) the carbon storage effect together with the substitution effect would have a significant impact on climate change mitigation if the ratio of newly constructed wooden buildings/furniture is gradually improved to $70 \%$ by 2050 .
\end{abstract}

Key words Kyoto protocol · Carbon reduction · Carbon storage $\cdot$ Low-carbon society $\cdot$ Biomass energy

Y. Tsunetsugu $(\bowtie)$

Department of Wood Engineering, Forestry and Forest Products

Research Institute, 1 Matsunosato, Tsukuba, Ibaraki 305-8687, Japan

Tel. +81-29-829-8310; Fax +81-29-874-3720

e-mail: yukot@ffpri.affrc.go.jp

M. Tonosaki

Department of Wood Properties, Forestry and Forest Products

Research Institute, Tsukuba, Ibaraki, Japan

Parts of this article were presented at the 55th and 56th Annual Meeting of the Japan Wood Research Society, Kyoto (March 2005) and Akita (August 2006), and the 4th Wood Science Symposium, Tokyo (April 2009)

\section{Introduction}

In the first commitment period of the Kyoto Protocol, Annex I countries have been faced with their own national greenhouse gas reduction targets. Japan set a target of $6 \%$ reduction from the 1990 levels, but so far, Japan's carbon emission has increased. Recently, the Japanese Cabinet approved the Action Plan for Establishing a Low-Carbon Society, in which it is recommended that Japan set a longterm goal of $60 \%-80 \%$ reduction of its current level of emissions by 2050 .

Since carbon absorbed by forests remains stored in the timber used for wood products, a change in the wood product stock can be evaluated as substantial removal/emission of atmospheric carbon. Although wood products were not included in the framework of carbon accounting in the first commitment period of the Kyoto Protocol, the carbon storage effect due to harvested wood products (HWP) might be taken into account in the next commitment period.

The other effect of carbon removal/emission brought about by wood utilization is the substitution effect. This effect has two separate aspects: energy saving by replacing highly energy-intensive materials, and reduction of carbon dioxide emitted through fossil fuel burning by using bioenergy sources as a substitute. Wooden materials generally consume less energy during processing compared to other materials such as steel, concrete, or plastics. Data differ depending on the source, but a database using input-output tables ${ }^{1}$ provides $1.051,2.988$, and $5.365 \mathrm{t}-\mathrm{C} /$ million yen for wood, concrete, and steel, respectively. The difference is still obvious when these materials are compared based on the same functional unit, e.g., the amount of carbon emission caused by the manufacture of materials for constructing a wooden building is about $38 \%$ of that for a reinforced concrete building. ${ }^{2}$ Hereafter, this effect is referred to as the energy saving effect to clearly distinguish it from the fossil fuel substitution effect. Since bioenergy is "carbon neutral," wood combustion does not contribute to the elevation of atmospheric carbon dioxide provided that the energy source is produced through sustainable forest management. 
With the recognition that wood utilization has a considerable impact on carbon removal/emission, HWP accounting has been discussed at the international level in anticipation of the next commitment period. The Intergovernmental Panel on Climate Change (IPCC) suggested three alternative approaches for HWP accounting: the stock-change approach, the production approach, and the atmospheric-flow approach, in addition to the current IPCC default approach where carbon storage in wood is not taken into account. ${ }^{3}$ The stock-change approach estimates changes in HWP carbon stock within a country. The production approach estimates changes in HWP carbon stock contained in the products made from wood harvested in the reporting country. The atmospheric-flow approach estimates fluxes of carbon to/from the atmosphere for the HWP pool within the national boundaries. The three approaches give the same results at a global level, but differ in national accounting results depending on whether the reporting country is producing or consuming HWP, ${ }^{4}$ which is confirmed by estimation using a simple spreadsheet model for assessing carbon storage based on FAOSTAT data.,

National HWP carbon accounting according to the three approaches using country-specific methods has been reported from Annex I countries such as Australia, ${ }^{7}$ Norway, ${ }^{8}$ the United Kingdom, ${ }^{9}$ Ireland,${ }^{10}$ Portugal,${ }^{11}$ New Zealand, ${ }^{12}$ Germany, ${ }^{13}$ and the United States. ${ }^{14}$ The Japanese government also reported HWP accounting for 2005 in response to the requirements of the 21st Subsidiary Body for Scientific and Technological Advice (SBSTA), but no studies have been made in an attempt to estimate Japan's carbon account for the next commitment period and after. Since the three approaches differ in incentives to achieve major policy goals related to climate, forest, trade, and waste,${ }^{15}$ it is highly important to evaluate the expected amount of carbon reduction due to HWP utilization and to develop a policy that takes full advantage of these carbon reduction effects.

In the present study, we developed a model for estimating the flow and stock of wood products in Japan's building, furniture, and paper sectors. The model enables quantitative estimation of the carbon storage effect, energy saving effect, and fossil fuel substitution effect due to HWP usage up to 2050 by means of lifetime analysis. To quantitatively calculate the carbon storage effect due to HWP utilization, it is necessary to determine the amount of HWP that is "in use" within a country per year (HWP stock). Since there are no reliable statistics for the output flow (amount of discarded waste) of HWP, while the input flow of HWP can be derived largely from national statistics, we employed a lifetime anal- ysis model. The impact of HWP and domestic timber utilization on carbon accounting was evaluated using the model developed.

\section{Method}

Basic structure of the model

The model consists of three parts that share the same basic structure but are specifically modified for three different industrial sectors: building, furniture, and paper. We assumed that buildings and furniture would decrease after construction/production according to the following equation:

$$
\text { Snt }=\operatorname{In} \cdot \frac{\exp \{-r(t-a)\}}{1+\exp \{-r(t-a)\}}
$$

where Snt is the remaining area/amount in year $t$ out of the input (starts/production) in year $n, I n$ is input in year $n, r$ is decreasing rate, $t$ is number of elapsed years, and $a$ is halflife. In the present study, $r$ was set to 0.2. If the input in year $n, n+1, n+2, \ldots, x$ decreases according to Eq. 1, the area/ amount of buildings or furniture in use in the year $x(C x)$ would be:

$C x=\sum_{n}^{x} \operatorname{Sn} x$

We assumed that paper would decrease after production according to an exponential equation:

Snt $=\operatorname{In} \cdot \exp (-\ln (2) / a)^{t}$

where Snt is the remaining amount in year $t$ out of the input in year $n, I n$ is input in year $n, a$ is half-life, $t$ is number of elapsed years. Equation 2 was applied to obtain the HWP stock in the paper sector.

\section{Extrapolated data}

The respective amount of HWP input to the building sector each year was calculated using the national production and import statistics ${ }^{16,17}$ and HWP input unit ${ }^{18}$ (amount of HWP stored per unit production, Table 1). HWP input to the furniture sector from 1985 to 2001 was obtained from the literature ${ }^{19}$ and was expanded utilizing its correlation to data on building starts. Paper production and imports were obtained from FAOSTAT. ${ }^{20}$ Household and sanitary paper and recovered paper were excluded from the analysis since they are not considered to contribute to HWP stock. These

Table 1. Wood input unit $\left(\mathrm{m}^{3} / \mathrm{m}^{2}\right)$ for buildings by structure type $\mathrm{e}^{18}$

\begin{tabular}{llllllll}
\hline & W & SRC & RC & S & CB & Others & non-W \\
\hline Sawn timber & 0.171 & 0.012 & 0.019 & 0.023 & 0.049 & 0.047 & 0.020 \\
Plywood & 0.016 & 0.003 & 0.004 & 0.004 & 0.007 & 0.007 & 0.004 \\
Particle or fiber board & 0.014 & & & & & & 0.003 \\
Total & 0.201 & & & & & & 0.027 \\
\hline
\end{tabular}

$\mathrm{W}$, wooden; SRC, steel-reinforced concrete; RC, reinforced concrete; S, steel; CB, concrete block

${ }^{a}$ Average of nonwooden structures weighted by area of three stories and fewer in building starts 
Table 2. Factors for conversion from product units to carbon

\begin{tabular}{lllll}
\hline & Sawn timber & Plywood & $\begin{array}{l}\text { Particle or } \\
\text { fiber board }\end{array}$ & Paper \\
\hline Density (oven-dry $\left.\mathrm{t} / \mathrm{m}^{3}\right)$ & 0.45 & 0.6 & 0.7 & \\
Carbon fraction $(\mathrm{t}-\mathrm{C} / \mathrm{t}$-material) & 0.5 & 0.5 & 0.45 & \\
Carbon factor $\left(\mathrm{t}-\mathrm{C} / \mathrm{m}^{3}\right)$ & 0.225 & 0.3 & 0.315 & $0.45(\mathrm{t} / \mathrm{t})$ \\
\hline
\end{tabular}

statistics were extrapolated from 1951 (1961 for paper due to data availability) to 2006 .

For the calculation in the production approach, the ratio of HWP made of domestic timber was worked out using the production/import statistics for the respective products.

We assumed that the average life span was 35 years for a wooden building and 30 years for a nonwooden building. This figure was set at 20 years for furniture. The half-life for paper was set at 2 years. To convert product units to carbon, we used the oven-dry densities and carbon fractions as shown in Table 2.

Scenarios for estimating HWP carbon account by 2050

The amount of new production in the three sectors from 2007 was predicted to decline in accordance with Japan's population decline. We estimated building starts and furniture production based on projections of population and number of households using a feasibility study for $70 \% \mathrm{CO}_{2}$ emission reduction by $2050,{ }^{21}$ which clarified that the population would drastically decrease to 100 million from 127 million in 2000, and that the number of households would drop from its peak in 2015 toward 2050. Nonresidential buildings were set to increase with a 1\% growth in GDP. Paper production was set to decrease gradually to $89 \%$ of the 2000 level by 2050, according to the projection in the study mentioned above. ${ }^{21}$

We considered two scenarios of wood utilization for future simulation. In the baseline scenario, the percentage of wooden buildings in building starts and the percentage of wooden furniture in production would remain at the 2005 level ( $35 \%$ for both). In the promotion scenario, the percentage of wooden buildings/furniture would increase sigmoidally to $70 \%$ by 2050 (buildings of three stories or fewer accounted for $69 \%$ of the area of newly constructed buildings in 2006) (Fig. 1). For both scenarios, the estimated domestic and imported timber/production supplies were provided by an external model (unpublished data). In the baseline scenario, domestic timber supply would slowly increase from $17 \mathrm{Mm}^{3}$ in 2006 to $25 \mathrm{Mm}^{3}$ by 2050 with a stable stumpage price. Domestic timber supply would increase to $42 \mathrm{Mm}^{3}$ by 2050 with high productivity and high stumpage price in the promotion scenario.

\section{Calculation}

The carbon storage effect was quantitatively evaluated using the three IPCC approaches. We included the imports

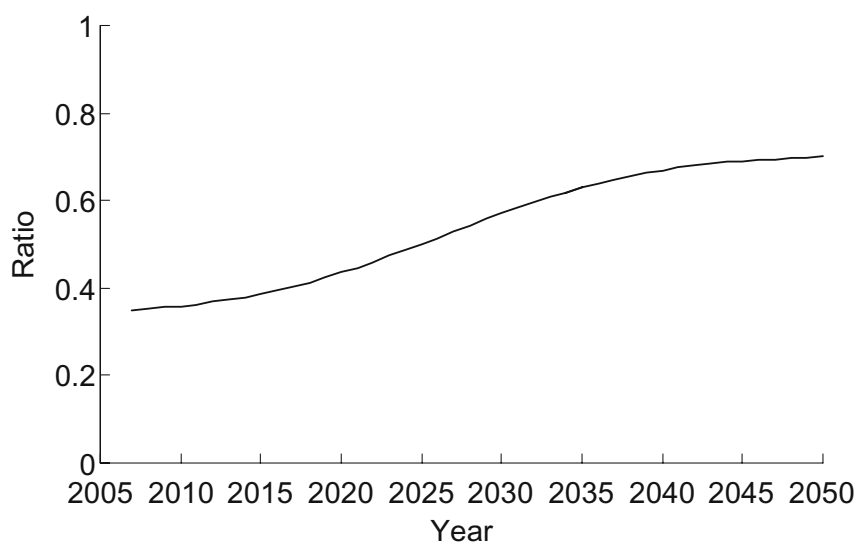

Fig. 1. Sigmoidal curve to determine the ratio of wooden buildings/ furniture in building starts/production after 2007 in the estimation model following the promotion scenario

of the "others" sector (other than the building, furniture, and paper sectors), which was an output from the external supply model, in the calculation for the atmospheric-flow approach. HWP input to the others sector is not considered to contribute to the HWP stock, and thus was not included in the calculation for the stock-change approach and production approach. HWP exports from Japan are sufficiently small to be excluded from the calculation.

The energy saving effect was calculated as the difference between the promotion scenario and the baseline scenario using the emission units necessary to produce construction materials for wooden and nonwooden buildings ${ }^{2}$ (i.e., the products of the increment in the number of wooden building in the promotion scenario compared to the baseline scenario, and the difference in emission units between a wooden building and a nonwooden one). Emission units of 0.059 and $0.095 \mathrm{t}-\mathrm{C} / \mathrm{m}^{2}$ were used for wooden buildings and nonwooden buildings, respectively. The unit for a nonwooden building was calculated as the average of nonwooden structures (steel-reinforced concrete, reinforced concrete, and steel) weighted by area of building starts for buildings of three stories and fewer.

To estimate the fossil fuel substitution effect, we considered the wood residue generated when producing and scrapping the buildings and furniture to be used as bioenergy resources. The energy efficiency per unit carbon was set to 0.5: twice as much carbon would be emitted when burning wood compared to fossil fuel for gaining the same amount of heat. 


\section{Results and discussion}

The adequacy of the model was confirmed by comparing the outputs of the building model to the national statistics for building stock. ${ }^{22}$ There were no comparable statistics for the furniture and paper sectors.

The carbon storage effect calculated using the three different approaches showed large differences (Fig. 2). As for the carbon storage effect from 1951 to 2006, the value evaluated by the stock-change approach was the largest, followed by the production approach. It was clarified that the carbon storage effect would be largely negative, i.e., a large emission for Japan, when evaluated by the atmospheric-flow approach. Since the production approach takes into account only HWP of domestic origin (as we excluded the exports), the results in which the values from the production approach were less than half those from the stock-change approach are valid for Japan, where the self-sufficiency in wood is low. The result for the atmospheric-flow approach is the difference between the inflow of domestic wood for use and the outflow of domestically used wood as waste. It is therefore also reasonable for Japan that the results in the atmospheric-
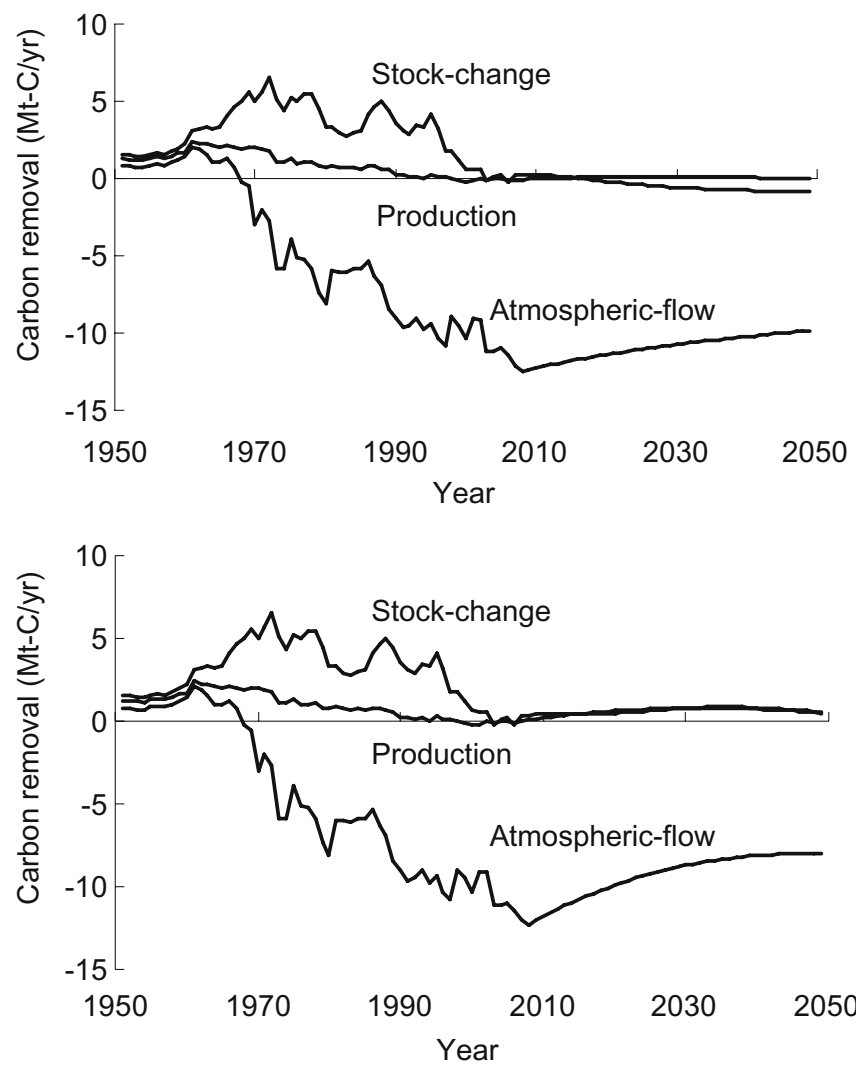

Fig. 2. Carbon storage effects calculated using the three alternative approaches suggested by the IPCC. Upper, calculated results for the baseline scenario, where the percentage of wooden buildings in building starts and the percentage of wooden furniture in production remain at the 2005 level (35\% for both). Lower, calculated results for the promotion scenario, where the percentage of wooden buildings/furniture increases sigmoidally to $70 \%$ by 2050 flow approach were large negative values, since the inflow of domestic timber for use is much smaller than the outflow of domestic and imported HWP. It should be noted, however, that the amount of carbon actually exported from emission was not excluded in the atmospheric-flow approach. There was an export of 1.2 Mt-C HWP in 2002, so the actual results for the atmospheric-flow approach, for example, would be $-8.0 \mathrm{Mt}-\mathrm{C} / \mathrm{yr}$ instead of the $-9.2 \mathrm{Mt}-\mathrm{C} / \mathrm{yr}$ plotted in the figure.

The carbon storage effect evaluated by the stock-change approach decreases after 2007 in the baseline scenario as the total stock of HWP decreases, and is overtaken in 2016 according to the results of the production approach; it becomes a negative value after 2017. These results are due to the scenario where the number of households reaches a peak in 2015 and decreases afterwards, and where the domestic timber supply slightly increases. The small improvement seen in the atmospheric-flow approach in the baseline scenario is also due to a rise in self-sufficiency.

The calculated results for all three approaches from 2007 improved in the promotion scenario. The improvement in the stock-change approach can be attributed to the increase in HWP stock with the increase in the ratio of wooden buildings and furniture in new production. The difference in the carbon storage effect over the baseline scenario reaches $1.4 \mathrm{Mt}-\mathrm{C} / \mathrm{yr}$ by 2050 . The rise in the ratio of wooden products also affects the results in the production approach and atmospheric-flow approach in conjunction with the total stock increase.

The amount of carbon removal due to the carbon storage effect is $0.085 \mathrm{Mt}-\mathrm{C} / \mathrm{yr}$ as evaluated by the stock-change approach and $0.046 \mathrm{Mt}-\mathrm{C} / \mathrm{yr}$ by the production approach in 2013-2018 (assumed to be the next commitment period) if the state of HWP utilization continues status quo, whereas it improves to $0.43 \mathrm{Mt}-\mathrm{C} / \mathrm{yr}$ in both approaches if $\mathrm{HWP}$ utilization is promoted (Fig. 3). The volume of carbon absorption in the stock-change approach or the production approach in the promotion scenario is approximately equivalent to $2 \%$ of Japan's reduction target (6\% of the 1990 total emission levels). In both cases, Japan would be charged

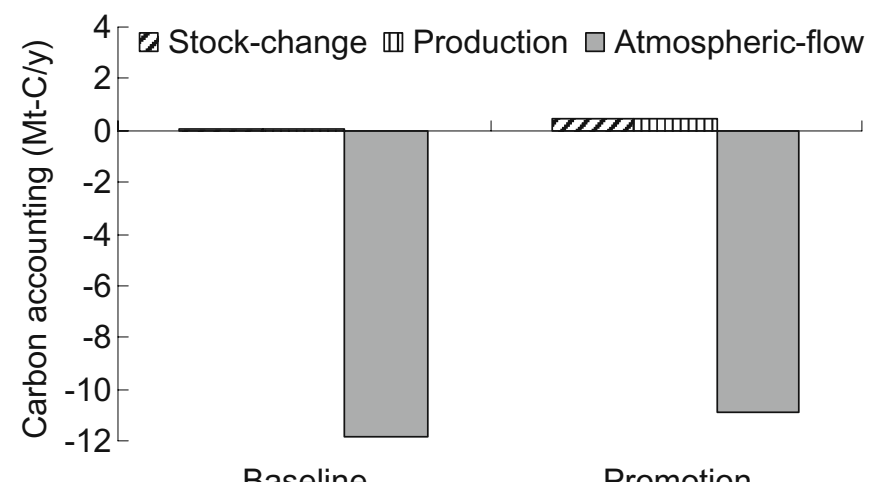

Fig. 3. Average annual amount of carbon removal by carbon storage effect in the period 2013-2018 calculated using the three alternative approaches suggested by the IPCC 


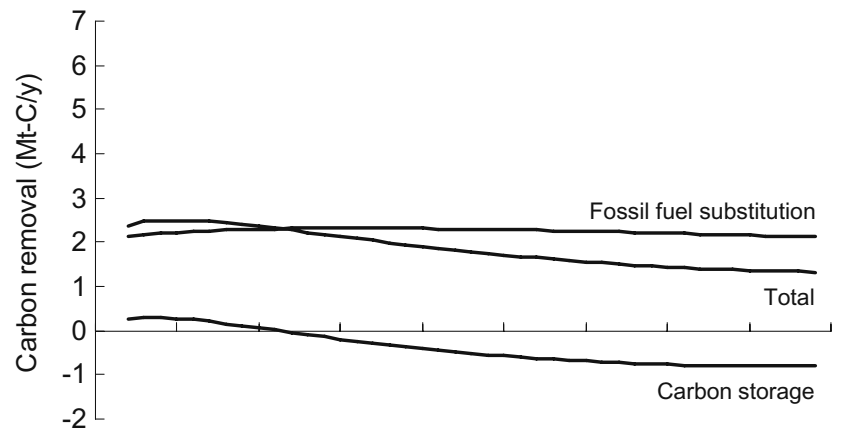

2005201020152020202520302035204020452050 Year

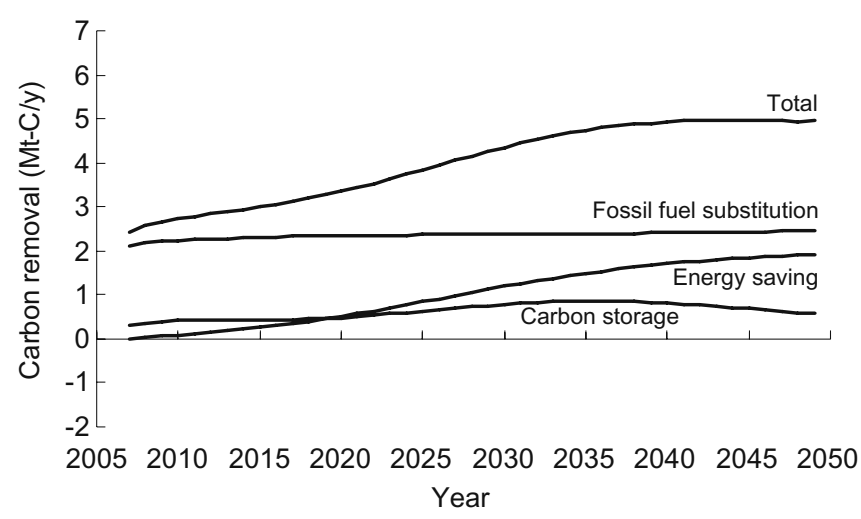

Fig. 4. Effects of carbon storage, energy saving, and fossil fuel substitution due to the utilization of harvested wood products in Japan. Upper, calculated results for the baseline scenario, where the percentage of wooden buildings in building starts and the percentage of wooden furniture in production remain at the 2005 level ( $35 \%$ for both). Lower, calculated results for the promotion scenario, where the percentage of wooden buildings/furniture increases sigmoidally to $70 \%$ by 2050

about $11 \mathrm{Mt}-\mathrm{C} / \mathrm{yr}$ carbon emissions due to HWP if calculated by the atmospheric approach.

The other two effects, energy saving and fossil fuel substitution, would provide substantial effects of carbon removal, at least compared to the carbon storage effect (Fig. 4). The fossil fuel substitution effect becomes almost constant at around $2 \mathrm{Mt}-\mathrm{C} / \mathrm{yr}$ in the baseline scenario. The carbon storage effect, which is the one calculated by the stock-change approach, results in a gradual decrease in total carbon removal from 2011 in the baseline scenario. The fossil fuel substitution effect constantly increases in the promotion scenario and reaches $2.5 \mathrm{Mt}-\mathrm{C} / \mathrm{yr}$ by 2050 . This enlargement in the promotion scenario is mainly due to the increase in wood waste when manufacturing and demolishing wooden buildings and furniture. The energy saving effect in the promotion scenario gradually elevates to 1.9 Mt-C/yr by 2050 , which is about $0.58 \%$ of the 2005 carbon emission due to energy consumption in Japan. ${ }^{23}$ The total of the three effects obviously increases and reaches nearly $5.0 \mathrm{Mt}-\mathrm{C} / \mathrm{yr}$ by 2050 , which is equivalent to $1.5 \%$ of the 1990 total emission level and is considered to have a significant impact on climate change mitigation policy in Japan.

\section{Conclusion}

We developed a model for estimating the flow and stock of wood products in Japan's building, furniture, and paper sectors. The model estimation from 1951 (1961 for paper) to 2050 revealed that (i) the carbon stock change in Japan due to HWP would be evaluated as a large emission if the atmospheric-flow approach is adopted, (ii) carbon reduction would not significantly increase if the ratio of newly constructed wooden buildings/furniture remains stable, and (iii) the carbon storage effect together with the substitution effect would have a significant impact on climate change mitigation if the ratio of newly constructed wooden buildings/furniture is gradually improved to $70 \%$ by 2050 . The present model did not take into account the energy saving effect in the furniture industry or any effects from other HWP pools such as bridges and other civil construction. The positive utilization of HWP clearly has significance for achieving a low-carbon society.

Acknowledgments This research was partly supported by the Global Environment Research Fund (B-60 and S-3) of the Ministry of the Environment, Japan.

\section{References}

1. Nansai K, Moriguchi Y, Tohno S (2002) Embodied energy and emission intensity data for Japan using input-output tables. National Institute for Environmental Studies, Tsukuba

2. Sakai K, Urushizaki N, Nakahara T (1997) Carbon dioxide emissions during production of construction materials in 1985 and 1990 and their influence on civil works (in Japanese). Environ Syst Res 25:525-532

3. Pingoud K, Skog KE, Martino DL, Tonosaki M, Xiaoquan Z (2006) Harvested wood products. In: Eggleston HS, Buendia L, Miwa K, Ngara T, Tanabe K (eds) 2006 IPCC guidelines for national greenhouse gas inventories. IGES, Hayama

4. Lim B, Brown S, Schlamadinger B (1999) Carbon accounting for forest harvesting and wood products: review and evaluation of different approaches. Environ Sci Policy 2(2):207-216

5. Skog KE, Pingoud K, Smith JE (2004) A method countries can use to estimate changes in carbon stored in harvested wood products and the uncertainty of such estimates. Environ Manag $33 \mathrm{suppl}$ (1):S65-S73

6. Pingoud K, Perälä AL, Soimakallio S, Pussinen A (2003) Greenhouse gas impacts of harvested wood products: Evaluation and development of methods. VTT Research Notes 2189, VTT Technical Research Centre, Espoo, pp 68-74

7. Borough C, Crawford H (2001) The development of a national wood products model. In: Schlamadinger B, Woess-Gallasch B, Cowie A (eds) Proceedings of the workshop carbon accounting and emissions trading related to bioenergy, wood products and carbon sequestration. IEA Bioenergy Task 38, Canberra, pp 5770

8. Flugsrud K, Hoem B, Kvingedal E, Rypdal K (2001) Estimating the net emission of $\mathrm{CO}_{2}$ from harvested wood products: A comparison between different approaches. Norwegian Pollution Control Authority, Oslo, pp 1-47

9. Thomson AM, Milne R (2005) Carbon stock changes due to harvested wood products in the UK. In: Milne R, Mobbs DC (eds) UK emissions by sources and removals by sinks due to land use, land use change and forestry activities. Department for the Environment, Food and Rural Affairs, London, pp 4.1-4.6

10. Green C, Avitabile V, Farrella EP, Byrneb KA (2006) Reporting harvested wood products in national greenhouse gas inventories: Implications for Ireland. Biomass Bioenerg 30(2):105-114 
11. Dias AC, Louro M, Arroja L, Capela I (2007) Carbon estimation in harvested wood products using a country-specific method: Portugal as a case study. Environ Sci Policy 10(3):250-259

12. Ford-Robertson J, Robertson K (2008) Forestry accounting options Report produced for Ministry of Agriculture and Forestry, NZ Policy under CC MAF POL_2008-10 (1101) Objective 2, Christchurch, pp 1-45

13. Rüter S (2008) Model of estimating carbon storage effects in wood products in Germany. In: Hetsch S (ed) Proceedings of the workshop on harvested wood products in the context of climate change policies. UNECE/FAO Timber Section, Geneva, pp 1819

14. Skog KE (2008) Sequestration of carbon in harvested wood products for the United States. Forest Prod J 58(6):56-72

15. Hashimoto S (2008) Different accounting approaches to harvested wood products in national greenhouse gas inventories: their incentives to achievement of major policy goals. Environ Sci Policy 11(8):756-771

16. Construction Research and Statistics Office, Policy Bureau, Ministry of Land, Infrastructure, Transport and Tourism, Japan (19512006) Statistics on building starts. In: Construction Research and Statistics Office, Policy Bureau, Ministry of Land, Infrastructure, Transport and Tourism, Japan (ed) Yearbook of construction statistics. Construction Research Institute, Tokyo

17. Research and Statistics Department, Minister's Secretariat, Ministry of International Trade and Industry (1985-2001) Production, producer's shipments and producer's inventory of finished goods: Furniture. In: Research and Statistics Department, Minister's Sec- retariat, Ministry of International Trade and Industry (ed) Yearbook of general merchandise statistics. Research Institute of International Trade and Industry, Tokyo

18. Tonosaki M, Tsunetsugu Y (2004) Timber input unit for buildings from "The investigation of construction materials and labor demand" (in Japanese). Wood Ind 59(8):360-362

19. Soma T, Arima T (2004) Estimation on the carbon stock in wooden furniture: A trial calculation on the amount of wood used for furniture production (in Japanese). In: Abstracts of the Annual Meeting of the Japan Wood Research Society. The Society, Tokyo, $54: 442$

20. The Statistics Division, The Food and Agriculture Organization of the United Nations (1961-2006) Production, import, export quantities: Paper and paper board. In: FAOSTAT, http://faostat.fao.org/. Accessed March 23, 2010

21. 2050 Japan Low-Carbon Society Scenario Team (2008) Japan scenarios and actions towards low-carbon societies (LCSs). NIES, Kyoto, $\mathrm{p} 8$

22. Local Tax Bureau, Ministry of Internal Affairs and Communications (1964-2006) Residential building. In: Local Tax Bureau, Ministry of Internal Affairs and Communications (ed) Brief Record of Prices of Fixed Properties. Local Tax Bureau, Ministry of Internal Affairs and Communications, Tokyo

23. Energy Supply and Demand Subcommittee, The Ministry of Economy, Trade and Industry (2008) Outlook for CO2 emission by energy consumption (in Japanese). In: Outlook for long-term energy supply and demand, http://www.enecho.meti.go.jp/ topics/080523b.pdf. Accessed March 23, 2010 